\title{
Study of Management of Cerebrospinal Fluid Rhinorrhea
}

\author{
Himanshu Raval ${ }^{1}$ \\ ${ }^{1}$ Department of Neurosurgery, Nathiba Hargovandas Lakhmichand \\ Municipal Medical College, Ahmedabad, Gujarat, India
}

\begin{abstract}
Address for correspondence Himanshu Raval, Department of Neurosurgery, Nathiba Hargovandas Lakhmichand Municipal Medical College, SVP Hospital Campus, Elisbrige, Ahmedabad-380006, Gujarat, India (e-mail: hims02929@gmail.com).
\end{abstract}
Abstract
Keywords
- CSF
- CSF rhinorrhea
- trauma
- intracranial
- extra cranial

Cerebrospinal fluid (CSF) rhinorrhea is a condition where the protective fluid that surrounds the brain finds its way into the nose and sinuses, often appearing as a very watery runny nose. In this study, we are looking for clinical picture, various available investigation and treatment modalities, and their outcomes. In this study, we include 60 patients diagnosed with CSF rhinorrhea irrespective of cause. Patient having similar clinical picture but ruled out by investigation are not included. We obtain result in terms of most common causative factor, common site, and efficacy of treatment, and can decide a favorable line of management with respect to different circumstances.

\section{Introduction}

Cerebrospinal fluid (CSF) rhinorrhea was first described in the second century AD by Galen, and his theory was that the CSF leaked into the nose through the pituitary and ethmoid regions. The correlation of posttraumatic rhinorrhea with leakage of CSF was made in the 17th century by Dutch surgeon, Bidloo the Elder. ${ }^{1}$ Dura mater of the brain is an important barrier for any infection to ascend intracranially. Any transdural event can cause breach in its integrity, causing leak of the cerebrospinal CSF, as evident from watery nasal discharge. Transdural event can be due to trauma, nasal surgery, tumors invading skull base, or may be spontaneous. CSF rhinorrhea ensues when the breach involves the nasal mucosa, periosteum, the bone forming the skull base in the region of nose and paranasal sinuses (PNS), endosteum, dura mater, and arachnoid mater. In each of these cases, the outcome is the same-CSF leak from the site of injury to dura and ascending infection through the defect, causing meningitis and related complications. ${ }^{2}$ CSF fistula is a serious and potentially fatal condition whose successful management requires a fundamental multidisciplinary approach. Until recently, the management of this condition was almost exclusively neurosurgical. $^{3}$
CSF leaks are generally classified as traumatic, iatrogenic, and spontaneous/idiopathic. Traumatic causes include both blunt and penetrating facial injuries. Iatrogenic causes include neurosurgical and otolaryngologic approaches to neoplastic disease as well as functional endoscopic sinus surgery (FESS). Most spontaneous, or primary, causes of CSF rhinorrhea are now thought actually to be secondary to elevations in intracranial pressure (ICP) that might be seen in patients with idiopathic intracranial hypertension (IIH). Congenital skull base defects and certain tumors can also lead to CSF rhinorrhea. ${ }^{4}$ Surgical repair of CSF leak site can be either through an intracranial or an extracranial approach. Endoscopic approach is a type of extracranial approach which has the advantage of being less invasive, no external surgical scar, excellent site localization with preservation of the surrounding anatomy, and shorter hospital stay. Over the past decade, functional endoscopic sinus surgery has contributed considerably to the surgical armamentarium, and the endoscopic approach is considered by some of those surgeons to have become the standard of care, especially in CSF leaks of the anterior and middle skull base. ${ }^{5}$ Although the endoscopic approach may be well-suited to the majority of cases encountered in otolaryngologic practice, it does not exhaust

(C)2022. Neurological Surgeons' Society of India.

This is an open access article published by Thieme under the terms of the Creative Commons Attribution-NonDerivative-NonCommercial-License, permitting copying and reproduction so long as the original work is given appropriate credit. Contents may not be used for commercial purposes, or adapted, remixed, transformed or built upon. (https://creativecommons.org/licenses/by-nc-nd/4.0/).

Thieme Medical and Scientific Publishers Pvt. Ltd. A-12, 2nd Floor, Sector 2, Noida-201301 UP, India 
the techniques with which the neurosurgeon must be conversant with in view of the full range of anatomic and pathophysiologic conditions confronted in neurosurgical practice. ${ }^{3}$

\section{Materials and Methods}

This is the analysis of 60 cases of CSF rhinorrhea presented in the department of neurosurgery, NHL Medical College and Sheth V.S. Hospital, Ahmedabad, during the time period of December 2008 to November 2018.

\section{Inclusion Criteria}

- Patient presented with traumatic head injury and have CSF rhinorrhea.

- Patient had past history of head trauma and presented with CSF rhinorrhea.

- Patient with spontaneous CSF rhinorrhea.

- Patient previously operated for other pathology and presented with postoperative CSF rhinorrhea.

\section{Exclusion Criteria}

- Patients with no CSF leakage or bony defect found in CT/ MR study are excluded.

The data are collected by the use of predefined proforma to collect relevant information of the patient. In all these cases, complete clinical examination was done. Relevant investigations were performed for individual patients.

Patients were evaluated, diagnosed, and classified using the following methods:

- History.

- Clinical examination.

- Biochemical and microbiological analysis of CSF.

- CT brain.

- CT PNS-axial and coronal cuts.

CT cisternogram/MR cisternogram.

All patients were investigated for CBS, renal and liver function, coagulation profile, viral marker of HIV, HBsAG, and blood grouping. Routine chest X-ray, USG chest and abdomen, and ECG were done. Patients with specific medical comorbidity were evaluated accordingly. Patients with spontaneous rhinorrhea underwent fundus examination and CSF manometry.

Leak site were classified into the following five locations:

- Anterior ethmoid roof.

- Posterior ethmoid roof.

- Sphenoid sinus.

- Cribriform plate.

- Frontal sinus.

All patients were given intravenous (IV) broad-spectrum antibiotics and oral antibiotic afterward.

In conservative treatment, patients were kept in supine position, given stool softener, and advised to avoid unnecessary staining. All patients were given acetazolamide $250 \mathrm{mg}$ tid dosage. Patients were evaluated for routine vitals and signs of meningitis. Patients were observed for 7 days.

In operative treatment, for intracranial approach, bicoronal skin flap and elevation of depressed fracture were done if necessary. CSF leak site was confirmed and fascia lata, temporalis fascia, or pericranium was used to repair leak. Dural substitutes were sutured in watertight fashion by silk 4-0.

For extracranial approach, we worked in coordination with the ENT department of our institute in evaluating and treating patients for endoscopic transnasal surgery. After observing the leak on endoscopy by doing Valsalva maneuver, fascia lata, fat and fibrin glue were applied over the defect. Nasal packing was done, and patient was kept as routine postoperative care.

All patients were operated under general anesthesia.

\section{Results}

The present study of CSF rhinorrhea is aimed at assessing the clinical profile, investigatory tool, and management of patients afflicted with it.

The study included 60 patients, of which 39 were male and 21 were female with age range from 6 to 78 years. Most the patients were young males belonging to the 3rd and 4th decade. Patients with CSF rhinorrhea presented with watery discharge from nose, which may or may not associated with other symptoms such as headache, fever, vomiting, and epistaxis. Categorizing the patients according to etiology, CSF rhinorrhea was classified as traumatic, spontaneous and iatrogenic, and in our study, most patients developed rhinorrhea due to traumatic cause, whether it may be road traffic accident, fall or assault. Increased prevalence of CSF rhinorrhea is correlated with increased incidence of trauma in that age group. A total of 26 patients younger than 40 years of age experienced rhinorrhea due to trauma.

We conclude in our study that the most common site of the leak is cribriform plate and frontal sinus. On correlating the etiology and site of the leak, cribriform plate defect was found to be more common in spontaneous leak, while frontal sinus leak was more common in traumatic leak.

\section{Discussion}

In our study, we conducted a study of 60 patients with CSF rhinorrhea of different etiology and presentation. We analyzed various demographic factors as well as the pathologic factor and treatment modality for the patients with CSF rhinorrhea.

In our study, the demographic factor related to CSF rhinorrhea shows male predominance, with $65 \%$ of the patients being male and $35 \%$ of patients being female. Lindstrom et al study in Wisconsin medical college had 53 patients, 28 were females and 25 were men. ${ }^{6}$ We found that age for presentation of complaint ranged from 6 years to 78 years, with mean age being 36.4 years. The maximum number of patients were found to be younger than 40 years of age. As much as $70 \%$ of the patients were below 40 years, of which $80 \%$ belonged to the 3rd and 4th decades of life. Lindstrom et al experienced that patients' age ranged from 21 to 72 years with mean age at repair being 47.6 years. We found in our study that the incidence of rhinorrhea was low in age groups at the extreme ends of the spectrum of and steady decline of incidence was seen with increasing age. 
Most of the patients were in their 3rd and 4th decades of life; also, we found $76 \%$ of patients were male and $24 \%$ of the patients were female in this group. So, CSF rhinorrhea was more common in young male patients ( $\mathbf{- T a b l e s} \mathbf{1}$ and $\mathbf{2}$ ).

We divided the patients into three categories according to etiology: traumatic, spontaneous, and iatrogenic. In our study, 46 patients (78.33\%) had rhinorrhea due to trauma, including road traffic accidents, falls, and assaults. Spontaneous rhinorrhea was seen in 12 patients (18.33\%) and iatrogenic rhinorrhea in 2 patients (3.34\%). Iatrogenic rhinorrhea developed in one patient operated for trigeminal neuralgia on the left side who developed left-sided rhinorrhea through mastoid air cells (MAC), and one patient was operated for endoscopic transnasal transphenoidal pituitary adenoma and developed CSF rhinorrhea in postoperative period through sphenoid sinus. Lindstrom et al experience in Wisconsin Medical college is as follows: traumatic (16; 28\%), iatrogenic (28; 49\%), and spontaneous (13; 22\%). ${ }^{(40)}$ In Beckhardt et al study, 80\% of cases were secondary to head trauma, while $16 \%$ were the result of operations in the nasal/paranasal cavities and skull base. Only approximately $4 \%$ of cases were considered nontraumatic or spontaneous. We obtained results similar to the Beckhardt et al study.

As noted previously, CSF rhinorrhea was more common with young male patients, which correlated with more road traffic accidents occurring among the young male population which, in turn, leads to the prevalence of rhinorrhea among young male patients of traumatic origin. Beckhardt et al in 1991 observed spontaneous leaks to be more common in females (male:female ratio $=1: 2$ ) in the 4 th decade of life. ${ }^{7}$

On analyzing the site of the leak, cribriform plate (46.66\%) was found to be the most common site for CSF leak, followed by frontal sinus (41.67\%) and ethmoidal sinus (8.33\%). Sphenoidal sinus and MAC leak were found in one patient (1.67\%) which was iatrogenic in origin. With further analysis of site of the leak with etiology of the rhinorrhea, we noticed that the most common site for CSF leak associated with spontaneous etiology was cribriform plate (66.67\%). None of the patients with spontaneous leak were found to be of frontal sinus origin. Spontaneous CSF rhinorrhea occurs in patients with high intracranial pressure, resulting in remodeling and thinning of the bones at the skull base, and also causing leak which actually acts as a safety valve. An intracranial neoplasm, hydrocephalus, or the benign intracranial hypertension act on the prolongation of arachnoid sleeves around the olfactory fibers. The dura at this area ruptures and lets out the CSF to decrease the intracranial pressure. Out of eight patients having spontaneous rhinorrhea, three had benign intracranial hypertension, two had hydrocephalus, and three had intracranial neoplasm.

But in traumatic etiology, frontal sinus defect was most common (54.34\%). Lindstrom et al experienced leak from cribriform plate up to $35 \%$, from frontal sinus $10.52 \%$, from sphenoid sinus $26.31 \%$, and ethmoidal sinus $26.31 \%$. One patient $(1.75 \%)$ has an iatrogenic leak from inferior clivus (- Tables 3 and 4). ${ }^{6}$

This study intends to evaluate the treatment modality. Out of 60 patients, 29 patients (48.33\%) were managed by conservative method and 31 patients (51.67\%) were operated by a variety of modalities. All the other patients who were managed conservatively had stopped CSF leak over a period of time except one who developed recurrence. Recurrent leak was also managed conservatively and this patient got resolution of symptoms. Success rate with this approach was $96 \%$. In properly selected patients, nonoperative management is ultimately successful in $90 \%$ of patients ${ }^{6}$ Most of the CSF leak spontaneously closed within 7 to 10 days. CSF leak persisting for $>7$ days had significantly increased risk of developing meningitis. ${ }^{9}$

A total of 31 operated patients were categorized in two groups, intracranial and extracranial approach. Intracranial approach was further divided into two groups, intracranial extradural and intracranial intradural approach ( - Table 5 ).

Out of 31 patients, 16 patients (51.62\%) were operated by intracranial intradural approach and 9 patients (29.03\%) by intracranial extradural approach. Westmore and Whittam et $\mathrm{al}^{13}$ and Park et al ${ }^{14}$ showed initial success rates of $80 \%$ and $60 \%$, respectively. Six patients (19.35\%) were operated by endoscopic transnasal transsphenoidal route. In our study, overall success rate with primary attempt for intracranial approach was $96 \%$, while with endoscopic transnasal transsphenoidal approach, it was 66.67\%. Dodson et al treated 29 cases of CSF

Table 2 Age-wise distribution of patients

\begin{tabular}{|l|l|l|}
\hline Age (years) & Male & Female \\
\hline $0-10$ & 1 & 0 \\
\hline $10-20$ & 3 & 3 \\
\hline $20-30$ & 4 & 2 \\
\hline $30-40$ & 20 & 13 \\
\hline $40-50$ & 6 & 2 \\
\hline $50-60$ & 2 & 0 \\
\hline $60-70$ & 0 & 1 \\
\hline $70-80$ & 1 & 0 \\
\hline Total & 39 & 21 \\
\hline
\end{tabular}

Table 1 Comparative studies of demographic profile ${ }^{6-8}$

\begin{tabular}{|c|c|c|c|c|c|}
\hline & & Present study & Lindstrom et $a^{6}$ & Safavi et $\mathrm{al}^{8}$ & Beckhardt et al \\
\hline \multirow[t]{2}{*}{ Age (year) } & Mean & 36.4 & 47.6 & 33 & \\
\hline & Decade & 3 rd \& 4th & 3 rd \& 4th & 4th & 4th \\
\hline \multirow[t]{2}{*}{ Gender } & Male & $65 \%$ & $53.00 \%$ & $59.50 \%$ & \\
\hline & Female & $35 \%$ & $47.00 \%$ & $40.50 \%$ & \\
\hline
\end{tabular}


Table 3 Comparative studies of clinicopathological profile

\begin{tabular}{|c|c|c|c|c|}
\hline & & Present study & Lindstrom et $\mathrm{al}^{6}$ & Beckhardt et al ${ }^{7}$ \\
\hline \multirow[t]{3}{*}{ Etiology } & Traumatic & $78.33 \%$ & $28.07 \%$ & $80 \%$ \\
\hline & Spontaneous & $18.33 \%$ & $22.80 \%$ & $4 \%$ \\
\hline & latrogenic & $3.34 \%$ & $49.12 \%$ & $16 \%$ \\
\hline \multirow[t]{5}{*}{ Site of leak } & Cribriform plate & $46.00 \%$ & $35.00 \%$ & \\
\hline & Frontal sinus & $41 \%$ & $10.52 \%$ & \\
\hline & Ethmoidal sinus & $8 \%$ & $26.31 \%$ & \\
\hline & Sphenoid sinus & $1.67 \%$ & $26.31 \%$ & \\
\hline & MAC & $1.67 \%$ & - & \\
\hline \multirow[t]{2}{*}{ Etiology a/w site (m/c) } & Traumatic & $54 \%(\mathrm{fs})$ & $37.5 \%$ (ср) & \\
\hline & Spontaneous & $66.67 \%$ (ср) & $46 \%(c p)$ & \\
\hline
\end{tabular}

Abbreviation: MAC, mastoid air cell.

Table 4 Etiology and site of leak in this study

\begin{tabular}{|l|l|l|l|l|l|l|}
\hline Etiology & $\begin{array}{l}\text { Cribriform } \\
\text { plate }\end{array}$ & Frontal sinus & $\begin{array}{l}\text { Sphenoidal } \\
\text { sinus }\end{array}$ & $\begin{array}{l}\text { Ethmoidal } \\
\text { sinus }\end{array}$ & MAC & Total \\
\hline Traumatic & 19 & 25 & 1 & 2 & 0 & 47 \\
\hline Spontaneous & 8 & 0 & 0 & 3 & 0 & 11 \\
\hline latrogenic & 0 & 0 & 1 & 0 & 1 & 2 \\
\hline
\end{tabular}

Abbreviation: MAC, mastoid air cell.

Table 5 Indication for approach

\begin{tabular}{|l|l|}
\hline Approach & Indication \\
\hline Intracranial & $\begin{array}{l}\text { 1. Acute or delayed traumatic leak from anterior } \\
\text { or middle fossa } \\
\text { 2. Anterior fossa leak with extrasellar intracranial } \\
\text { mass } \\
\text { 3. Congenital anomaly of brain } \\
\text { 4. Definable dysplasia of the anterior or middle } \\
\text { fossa } \\
\text { 5. Postoperative leak after anterior or middle } \\
\text { fossa surgery } \\
\text { 6. Complex penetrating injuries involving } \\
\text { cerebral tissue as well as extracranial structures } \\
\text { 7. When craniotomy is indicated for other } \\
\text { reasons } \\
\text { 8. Whenever a significant dural hiatus is } \\
\text { demonstrable }\end{array}$ \\
\hline Extracranial/ & $\begin{array}{l}\text { 1. Clearly defined "spontaneous" leaks from the } \\
\text { anterior fossa, including the cribriform fossa and } \\
\text { fovea ethmoidalis } \\
\text { 2. Postoperative leaks after treatment of sellar } \\
\text { and parasellar lesions }\end{array}$ \\
\hline
\end{tabular}

rhinorrhea with endoscopic techniques. As much as 75\% had resolution after their initial repair. ${ }^{10}$ Lanza et al ${ }^{15}$ reviewed 36 patients who underwent endoscopic repair of CSF fistulas. During the first attempt, successful endoscopic repair was achieved in $94 \%$. Lindstrom et al. reported success rate of $91 \%$ with the endoscopic closure. ${ }^{6}$ Most case series have reported success rates of 90 to $95 \%$ with the endoscopic repair and 70 to $80 \%$ with intracranial repair of CSF rhinorrhea.

Fascia lata graft material had been used for different approach. In meta-analysis, Hegazy et al found no statistically significant difference among different graft techniques and materials. ${ }^{11} \mathrm{He}$ also advocated the use of lumber drain for 3 to 5 days postoperatively with idiopathic, traumatic, and recurrent leak, with large meningocele herniation.

Recurrence following initial successful relief of symptoms was seen in four patients (6.67\%). Recurrence was seen in 1 (3.44\%) conservatively treated patient, 1 (4\%) intracranially operated patient, and 2 (33\%) endoscopically operated patients. In literature, recurrence rate of intracranial route is $17.6 \%$ and of extracranial route is $28.1 \%$. The endonasal route has recurrence rate of $14.3 \%$ (- Tables 6 and 7 )., ${ }^{6,10,12}$

Complications following surgical treatment of CSF rhinorrhea was seen in five patients. Out of 5, one patient (16.66\%) was operated by endoscopic repair who developed recurrent leak, and the remaining 4 patients (16\%) were operated by intracranial repair. Death following CSF rhinorrhea treatment was seen in one patient (1.67\%) due to meningitis in the postoperative period. Gassner et al stated the rate of complication in intracranial approach was higher (12.9\%) than extracranial approach (3.2\%). ${ }^{12}$

\section{Conclusion}

Patients with CSF rhinorrhea are managed by both conservative approach and surgical approach. Patients with traumatic etiology usually show a self-limiting course and leaks subside within 3 to 14 days. Persistent leak or spontaneous leak require surgical intervention. The method of closure may vary. But the identification of the leak site and the plane between dura and the bone around the defect is an important 
Table 6 Comparative studies of management modality and success rate

\begin{tabular}{|l|l|l|l|l|}
\hline \multirow{2}{*}{ Conservative } & & Present study & Lindstrom et al $^{6}$ & Dodson et al $^{10}$ \\
\hline \multirow{2}{*}{ Intracranial } & Duration mean(days) & 7 & 7 & \\
\cline { 2 - 5 } & Success & $96 \%$ & $90 \%$ & \\
\hline Endoscopic & 1 st attempt & $96 \%$ & $89 \%$ & $100 \%$ \\
\cline { 2 - 5 } & 2nd attempt & $100 \%$ & $91 \%$ & $75 \%$ \\
\hline
\end{tabular}

Table 7 Comparative studies of complication

\begin{tabular}{|l|l|l|l|}
\hline \multirow{3}{*}{ Complication } & Overall & $\begin{array}{l}\text { Present } \\
\text { study }\end{array}$ & Gassner et al ${ }^{12}$ \\
\cline { 2 - 4 } & Intracranial & $16.10 \%$ & $8.40 \%$ \\
\cline { 2 - 4 } & Endoscopic & $16.60 \%$ & $12.90 \%$ \\
\hline
\end{tabular}

determinant of the success rather than the choice of material. Patients operated by extracranial route have favorable outcome in terms of short hospital stay and less morbidity as infection, meningitis and wound leak are less as compared with intracranial route. But recurrence rate is more with endoscopic route. Both intracranial and extracranial approach are feasible options for treatment of CSF rhinorrhea. Selection between the two is dependent on the etiology and site of leak. Morbidity and resolution of the leak is comparable among the two approaches, and it is more associated with the disease itself rather than the method of treatment.

\section{Fuding}

None.

\section{Conflict of Interest}

None declared.

\section{References}

1 Herbowski L. The maze of the cerebrospinal fluid discovery. Anat Res Int 2013;2013:59602710.1155/2013/596027

2 Cerebrospinal fluid leak. Available at: https://my.clevelandclinic.org/health/diseases/16854-cerebrospinal-fluid-csf-leak accessed on 21/08/2019. Accessed November 26, 2020

3 Management of Cerebrospinal Fluid Leaks. Available at: https://neupsykey.com/management-of-cerebrospinal-fluid-leaks. Accessed November 26, 2020
4 Marchiano E, Carniol ET, Guzman DE, Raikundalia MD, BaredesS,EloyJA.AnAnalysisofPatientsTreatedforCerebrospinal Fluid Rhinorrhea in the United States from 2002 to 2010. J Neurol Surg B Skull Base 2017;78(1):18-23

5 Endoscopic Repair of CSF Rhinorrhoea: A Review of its Efficacy and Success Rate Repository. Available at: http://repository-tnmgrmu.ac.in/2428/. . Accessed November 26, 2020

6 Lindstrom DR, Toohill RJ, Loehrl TA, Smith TL. Management of cerebrospinal fluid rhinorrhea: the Medical College of Wisconsin experience. Laryngoscope 2004;114(6):969-974

7 Beckhardt RN, Setzen M, Carras R. Primary spontaneous cerebrospinal fluid rhinorrhea. Otolaryngol Head Neck Surg 1991; 104(4):425-432

8 Safavi A, Safavi AA, Jafari R. An empirical approach to the diagnosis and treatment of cerebrospinal fluid rhinorrhoea: an optimised method for developing countries. Malays J Med Sci 2014; 21(5):37-43

9 Abuabara A. Cerebrospinal fluid rhinorrhoea: diagnosis and management. Med Oral Patol Oral Cir Bucal 2007;12(5): E397-E400

10 Dodson EE, Gross CW, Swerdloff JL, Gustafson LM. Transnasal endoscopic repair of cerebrospinal fluid rhinorrhea and skull base defects: a review of twenty-nine cases. Otolaryngol Head Neck Surg 1994;111(5):600-605

11 Hegazy HM, Carrau RL, Snyderman CH, Kassam A, Zweig J. Transnasal endoscopic repair of cerebrospinal fluid rhinorrhea: a meta-analysis. Laryngoscope 2000;110(7):1166-1172

12 Gassner HG, Ponikau JU, Sherris DA, Kern EB. CSF rhinorrhea: 95 consecutive surgical cases with long term follow up at Mayo clinic, Department of Otorhinolaryngology, mayo clinic. Am J Rhinol 1999;13(6):439-47

13 Westmore, GA and Whittam, DE. Cerebrospinal fluid rhinorrhoea and its management. Br J Surg. 1982;69: 489-492

14 Park JI, Strelzow V, Friedman WH: Current management of cerebrospinal fluid rhinorrhea. Laryngoscope. 2009;93: $1294-1300$

15 Lanza DC, O'Brien DA, Kennedy DW. Endoscopic repair of cerebrospinal fluid fistulae and encephaloceles. Laryngoscope. 1996;106(9 Pt 1):1119-1125 